\title{
Geographical distribution of chronic kidney disease of unknown origin in North Central Region of Sri Lanka
}

\author{
J M K B Jayasekara' ${ }^{1}$ D M Dissanayake ${ }^{1}$, S B Adhikari², P Bandara³ \\ (Index words: geographical distribution, chronic kidney disease, renal failure, GIS mapping)
}

\begin{abstract}
Objectives In early nineties investigators noticed an alarmingly high incidence of an apparently new form of chronic kidney disease of unknown aetiology (CKD-U) in some parts of Sri Lanka. The aim of the study was to investigate the geographical distribution of CKD-U using GIS and GPS mapping.
\end{abstract}

Methods Community based information was collected from 11,630 patients for GIS mapping using ARC 9.2 software. Based on GIS mapping, two locations were selected for GPS mapping to locate the households of 863 CKD-U patients with reference to reservoirs, irrigation canals and the topography of the areas.

Results GIS mapping indicated five high prevalence areas of CKD-U. Communities who consumed water from natural springs showed a low prevalence of the disease. GPS mapping showed that most of the affected villages were located below the reservoirs and canals with stagnant irrigated water.

Conclusion Epidemiological data on geographical distribution infers that while older foci of CKD-U are persisting, there is an emergence of new foci with time. The location of the affected villages below the level of the reservoirs/canals may indicate the possibility of draining of irrigated water to the shallow wells of the households, which is the source of drinking water.

Ceylon Medical Journal 2013; 58: 6-10

\section{Introduction}

Chronic kidney disease (CKD) is defined as either kidney damage or decreased kidney function for a period of three months or more [1]. It is characterised by progressive destruction of renal mass with irreversible sclerosis and loss of nephrons over a long period of time depending on the underlying aetiology. CKD is a slowly progressive disease, which requires dialysis or transplantation at the end-stage. It is an emerging health problem all over the world [2]. The disease is often associated with poor prognosis and it incurs economic burden on the patient, family, community and the country as a whole.
Common causes of CKD include diabetes mellitus, hypertension, urological diseases and glomerulonephritis. Toxins, collagen vascular diseases and infections are rare causes of CKD. Sri Lanka is an island in the Indian Ocean below the southern tip of India with a special topography. The island with a landmass of $65,525 \mathrm{~km}^{2}$ has a central massif with its tallest peak rising 2,500 meters above sea level. One hundred and three river basins spread radially from the central hills outward to the coastal plains. The island receives an average of $1800 \mathrm{~mm}$ rainfall from two monsoons. The region in the south-west quadrant (wet zone) receives an annual rainfall of 2,200 $\mathrm{mm}$ and covers one third of the country. Dry zone has a rainfall of about $2,000 \mathrm{~mm}$ and encompases $2 / 3$ of the country. The dry zone of the country is characterised by an intricate network of man made reservoirs and canals that provide water for paddy cultivation and for human and livestock use. However, CKD is abundant only in one part of the dry zone namely North Central region of the country.

In early nineties investigators in Sri Lanka have noticed an alarmingly high incidence of a new form of chronic kidney disease of unknown aetiology (CKD-U) in the North Central region of Sri Lanka. This kidney disease was not related to any of the known causes such as diabetes mellitus, hypertension and infection [3]. However, histopathology of affected kidneys showed tubulo interstitial nephritis, which is suggestive of a toxic aetiology. Researchers who investigated the disease proposed a number of risk factors including high level of fluoride in ground water, heavy metals such as cadmium, exposure to inorganic pesticides, use of aluminium containers for cooking and orchratoxin [4-7].

Although many studies on the aetiology of the disease were carried out by different research groups, a comprehensive epidemiological study has not yet been reported. As such, identification of the aetiology has become a difficult task.

Geographic information systems (GIS) and geographic position system (GPS) are computer-aided database management and mapping technology that organises and stores large amounts of multi-purpose

${ }^{1}$ Department of Pathology, Faculty of Medicine, University of Peradeniya, ${ }^{2} G S P$ analyst, Mahaweli Development Authority, Kotmale and ${ }^{3}$ Regional Director's Office, Anuradhapura, Sri Lanka.

Correspondence: DMD, e-mail: <dhammika62@gmail.com>. Received 18 September and revised version accepted 12 November 2012. Competing interests: none declared. 
information. Health mapping has evolved from Dr. John Snow's cholera death mapping in mid-nineteenth century to the latest Internet-based mapping. GIS is particularly useful to health professionals and administrators in planning and day-to-day management $[8,9]$. It offers powerful tools to determine geographical distribution and variation of diseases, and their prevalence and incidence. GIS has been successfully used in the management of many vector-borne diseases $[10,11]$.

In this study, we attempted using GIS and GPS technologies to study the geographical distribution of CKD-U, which is an important non communicable health problem in Sri Lanka. The present study was carried out with the aim of studying demographic characteristics of the patients, geographical distribution of the disease, location of households of the CKD-U patients in relation to reservoirs, irrigation canals and the topography of the affected area that would help identify potential aetiological factor/s, which could be associated with the disease.

\section{Methods}

In the first part of the study Geographical Information System (GIS) mapping was used (ARC 9.2 software) to study the geographical distribution of the disease. Information was collected with reference to basic demographic data and respective addresses of 11,323 chronic kidney disease patients who attended community renal clinics that were specially established to follow up CKD-U patients and hospital nephrology clinics and in high prevalence areas. Community based data collection was carried out with precautions to prevent counting the same patient twice or more. The patient density per each Grama Niladhari Division (GN) was calculated using the ARC 9.2 software. Subsequently the patient density was expressed in relation to 1000 population in each Grama Niladhari division [12]. Based on the findings of the GIS mapping, two locations, one area with a large reservoir (Padaviya) and another area with multiple small reservoirs (Nikawewa) were selected for further studies. Geographical Position System (GPS) mapping was used to study the location of households of the CKD-U patients in relation to reservoirs, irrigation canals and the topography of the two selected areas. There were 1100 and 97 reported patients from Padaviya and Nikawewa respectively. Homes of these registered patients were visited to record the GPS coordinates, collect demographic data and to reconfirm the diagnosis using documentary evidence. Due to unavailability of patients, migration, lack of information or subjects, who did not fulfill the diagnostic criteria, the sample was restricted to 863 during home visits (796 and 67 patients from Padaviya and Nikawewa respectively). The diagnostic criteria used for CKD-U includes absence of diabetes mellitus, hypertension, urinary tract infections or other renal diseases in the history, presence of urinary protein one plus or more in sulphosalicylic acid test on two occasions and presence of radiological / pathological evidence of chronic kidney disease.

\section{Results}

The demographic information showed that the male: female ratio of the disease was 2.4: 1 . CKD-U is more prevalent in the age group over 40 years with a mean age of $54.7 \pm 8$ years (Figure 1 ). Out of the total, $90 \%$ of the patients were farmers. The source of drinking water was shallow wells (92\%), tube wells (7\%) and water reservoirs (1\%). CKD-U was present even among patients who consumed boiled water exclusively for life. Clustering of the disease was observed in $30 \%$ of the patients.

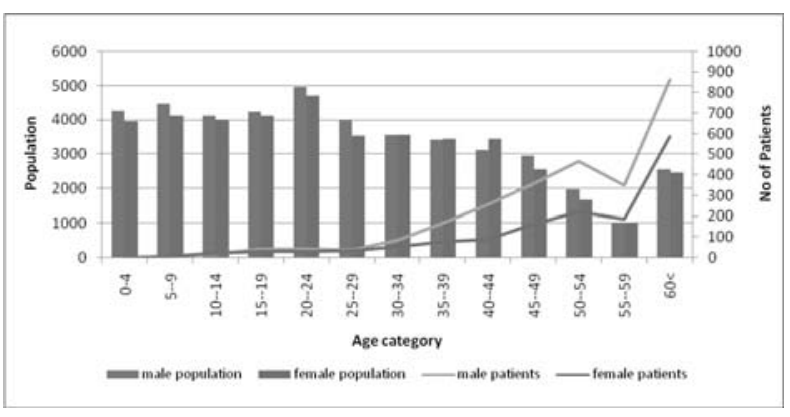

Figure 1. Age and sex distribution of CKD-U patients in Medawachchiya, Padaviya and Kebithigollewa areas.

The epidemiological data indicated three high prevalent areas (Figure 2) in the region namely Medawachchiya (identified 22 years ago), Padaviya (identified 20 years ago) and Girandurukotte (identified 14 years ago). In addition, two smaller foci have been identified in Medirigiriya (identified 10 years ago) and Nikawewa (identified 7 years ago). Epidemiological data infers that there is an emergence of new foci with time, while older foci are persisting. Low prevalence of the disease was noted in communities (some villages of Kebithigollewa) who consume water from natural springs for drinking (Figure 3). Figure 4 shows the distribution of patients in Girandurukotte, mainly a paddy farming area that is supplied by Ratkinda and Ulhitiya reservoirs. The disease is reported only among the villagers who live on the left bank of the Mahaweli river supplied by the two reservoirs while those who live on the right bank supplied by the natural springs are not affected. Figure 3 shows distribution of patients in Padaviya - another affected paddy farming area supplied by the Padaviya reservoir and the patient distribution in Medawachchiya area where a high density of smaller reservoirs is seen. GPS mapping shows that most of the affected villages are below the reservoir or canals (Figure 5). Area with the lowest altitude is affected by the disease. 


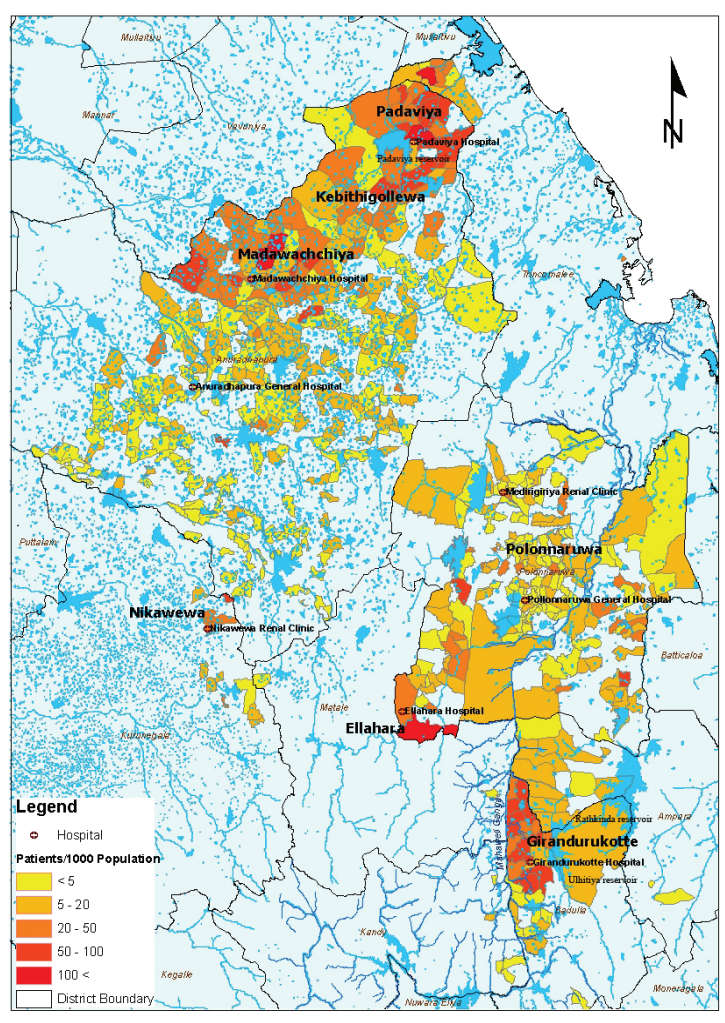

Figure 2. Geographical distribution of CKD-U patients in north central region attending hospitals/ renal clinics.

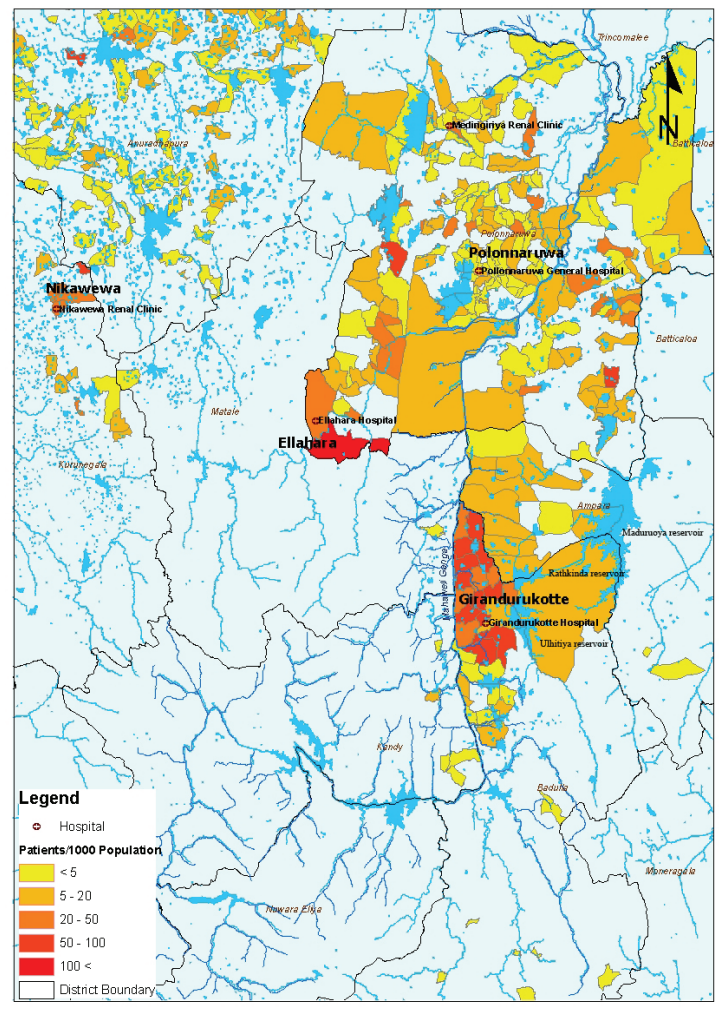

Figure 4. Distribution of CKD-U patients in Girandurukotte and Polonnaruwa.

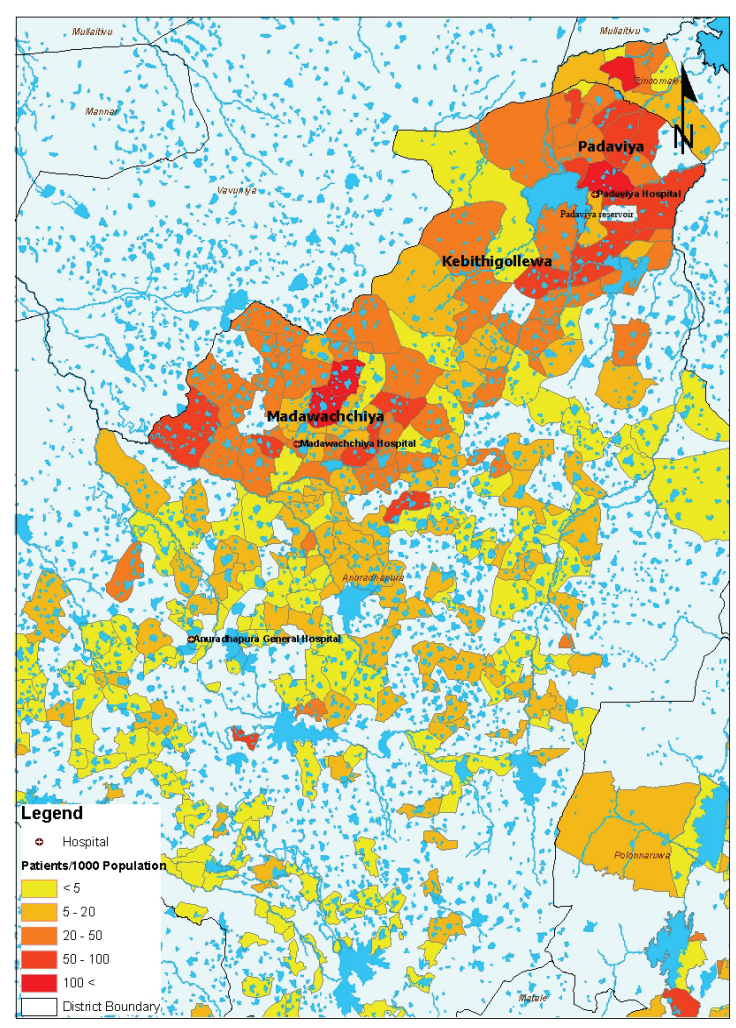

Figure 3. Distribution of CKD-U patients in Padaviya and Medawachchiya.

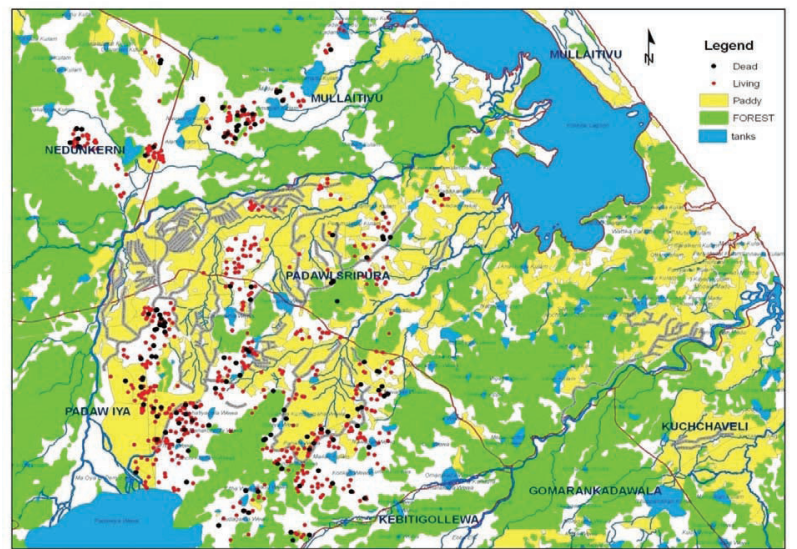

Figure 5. Location of the households of CKD-U patients in Padaviya. 


\section{Discussion}

The geographical distribution of the CKD-U shows that the disease is confined to some areas of the dry zone predominently in the North Central region (NCR), which includes villages of North Central, North Western and Uva provinces. Though the population at risk is scattered in the NCR, a large number of patients have been detected in Medawachchiya, Padaviya and Girandurukotte with two smaller foci in Medirigiriya and Nikawewa. It has been observed that all five regions affected with the CKD-U encompass a well developed irrigation system comprising of either one or two large reservoirs (Padaviya and Ratkinda/Ulhitiya) or a cluster of small reservoirs (Medawachchiya and Nikawewa). Water from these reservoirs is mainly used for agricultural purposes. However, the people who live in these areas consume water from shallow wells for their daily needs except bathing. These shallow wells are purposely positioned close to the irrigation canals and most are downstream of the canal so that the dwellers can gain water without digging too deep. Water levels of these shallow wells are proportionate to the water levels of the canals indicating that the ground water table is recharged from irrigation canals and reservoirs. Therefore, the ground water level fluctuates proportionately with the water level of the reservoirs and canals. This shows that there is a definite seepage of water from these canals to the shallow wells. As such, it is clear that almost all these shallow wells are fed by irrigation canals and not by natural springs. It has been observed that the prevalence of the disease is comparatively low in the villages where natural spring water is available for drinking and cooking.

Observations of the study reveal that the exposure to the aetiological agent remains unchanged and new disease foci are reported to be emerging. Therefore, prospective surveillance studies and regular screening programmes are essential to combat CKD-U. The reported familial occurrence of the disease with no evidence of clear Mendelian inheritance could be due to exposure of the siblings to the aetiological agent rather than direct genetic/inherited background for the disease. Similarly, familial occurrence and location of the affected house holds in the lowest lying area has been observed in Balken nephropathy too, where the causative agent is supposed to be toxic in nature [13-18]. Disease preponderance in males may be due to their frequent exposure to the aetiological agent than females. This could also be due to another unknown contributory factor that operates in males which increases the risk of the disease.

In conclusion, the characteristic geographical distribution of the disease related to stagnant irrigated water indicate the possibility of an environmental factor related to water in the pathogenesis of the disease. The use of water from the shallow wells for drinking by the affected population indicates the possibility that the aetiological agent is water soluble.

\section{Acknowledgements}

The authors acknowledge the South Asian Clinical Toxicology Research Collaboration for partly funding this study.

\section{References}

1. Levey AS, Coresh J, Balk E, et al. National Kidney Foundation Practice Guidelines for Chronic Kidney Disease: Evaluation, Classification, and Stratification. Annals of Internal Medicine 2003; 139: 2137-47.

2. Eknoyan G, Lameire N, Barsoum R, et al. The burden of kidney disease: Improving global outcomes. Kidney International 2004; 66: 1310-4.

3. Wanigasuriya KP, Peiris John RJ, Wickremasinghe R, et al. Chronic renal failure in North Central Province of Sri Lanka: an environmental exposure induced disease. Transactions of the Royal Society of Tropical Medicine and Hygiene 2007; 101: 1013-7.

4. Herath KRPK, Ileperuma OA, Dharmagunawardhane HA, et al. Environmental health risk factors for the chronic renal failure in Sri Lanka 31st Congress on Science and Technology of Thailand at Suranaree University of Technology, 18-20 October 2005.

5. Bandara RS, Senevirathna DMAN, Dasanayake DMRSB, et al. Chronic Renal Failure among farm families in cascade irrigation system in Sri Lanka associated with elevated dietary cadmium levels in rice and freshwater fish (Tilapia). Environmental Geochemistry and Health 2008; 3: 465-78.

6. Peiris John RJ, Wanigasuriya JKP, Wickremasinghe AR, et al. Exposure to acetylcholinesterase-inhibiting pesticides and chronic renal failure. Ceylon Medical Journal 2006; 51 : 42-3.

7. Wanigasuriya KP, Peiris H, Ileperuma N, et al. Could ochratoxin A in food commodities be the cause of chronic kidney disease in Sri Lanka? Transactions of the Royal Society of Tropical Medicine and Hygiene 2008; 102: 726-8.

8. Johnson S. The Ghost Map. Riverhead Books. p. 206. ISBN 1-59448-925-4. 2006.

9. Colledge M, Maxwell H, Parker R, Morse DJ. Geographic information Systems (GIS) in general practice: a new tool for needs assessment. Journal of Informatics in Primary Care 1996; 31: 7-11.

10. Balaji LN. GIS in health. GIS@development 2000;4: 17-20.

11. SrivastavaA, Nagpal BN. Mapping malaria.GIS@development 2000; 4: 28-31

12. Estimated population by GN divisions and age and sex. Census and Statistics report 2009.

13. Tatu CA, Orem WH, Finkelman RB, Feder GL. The etiology of Balkan nephropathy: still more questions than answers. Environmental Health Perspective 1998; 106: 689-700.

14. Èeoviæ S, Hrabar A, Šariæ M. Epidemiology of Balkan endemic nephropathy. Food and Chemical Toxicology 1992; 30: $83-8$. 
15. Craciun E, Rosulescu I. On Danubian endemic familial nephropathy (Balkan nephropathy). American Journal of Medicine 1970; 49: 774-9.

16. Toncheva D, Dimitrov T. Genetic predisposition to Balkan endemic nephropathy. Nephron 1996; 72: 564-9.
17. Mandal AK. Sindjic M, Sommers SC. Kidney pathology in endemic nephropathy. Clinical Nephrology 1987; 27: 304-8.

18. Ferluga D, Hvala A, Vizjak A, Trnacevic S, Halilbašic A. Renal function, protein excretion, and pathology of Balkan endemic nephropathy. III. Light and electron microscopic studies. Kidney International 1991; 40 (Sup): S57-67.

\title{
Trends and determinants of childhood stunting and underweight in Sri Lanka
}

\author{
R P Rannan-Eliya ${ }^{1}$, S M M Hossain ${ }^{2}$, C Anuranga ${ }^{1}$, R Wickramasinghe $^{1}$, R Jayatissa ${ }^{3}$, A T P L Abeykoon ${ }^{3}$
}

(Index words: stunting, wasting, inequality, children, maternal height, WHO growth standard)

\begin{abstract}
Introduction Child undernutrition is a major risk factor for child mortality and adult ill-health. Despite substantial progress in most health indicators, undernutrition remains high in Sri Lanka, with recent trends being unclear, owing to methodological differences in national surveys.

Methods This study uses data from the 1987, 1993, 2000 and 2006-07 Demographic and Health Surveys (DHS) and the 2009 Nutrition and Food Security Survey (NFSS) to investigate trends and determinants of child undernutrition in Sri Lanka. The prevalence rates of stunting, underweight and wasting were re-estimated using the 2006 WHO growth standards to ensure consistency. Multivariate regression analysis was then undertaken to analyse the determinants of height-forage in children aged 9-23 months, and 24-59 months, and the relative impact of key factors was assessed using prediction models.

Results Stunting and wasting substantially improved from 1987 to 2000, but rates stagnated from 2000 to 2006/07. Whilst economic inequalities in under nutrition were greater than in most other countries, the multivariate analysis found that maternal height, household wealth, length of breast-feeding and altitude are significant determinants of stunting, but differences in child feeding practices and other factors were not. Of these, maternal height and household wealth had the most influence.

Conclusion The results are consistent with the finding that food insecurity is the main driver of undernutrition, but more research is required to validate this. The strong relationship of child height with maternal height suggests
\end{abstract}

that epigenetic factors, proxied by short maternal height, constrain the applicability of the WHO growth standards in Sri Lanka.

Ceylon Medical Journal 2013; 58: 10-18

\section{Introduction}

Childhood under nutrition, manifesting as stunting, underweight and wasting, remains a substantial problem in Sri Lanka. Long-term sequelae include reduced cognitive ability and school performance, lower economic productivity, and decreased offspring birth weight [1]. Children who are undernourished in the first two years and put on weight rapidly later are at higher risk of chronic diseases, such as diabetes and ischaemic heart disease, both of which are increasing in Sri Lanka. Recent surveys have reported deteriorating trends in child malnutrition, but the published statistics lack comparability [2-5]. Our study re-examines the data to estimate trends and disparities, and investigate determinants of stunting.

\section{Methods}

We used data from all relevant, recent, national surveys: the DHS 1987, 1993, 2000 and 2006-07 surveys of the Department of Census and Statistics and the Medical Research Institute's NFSS 2009 [7] [2-5]. The DHS surveys exclude the Eastern (EP) and Northern (NP) Provinces, except for the1987 and 2006-07 surveys, which partially or completely covered EP. The NFSS 2009 used a two-stage, cluster sample design to survey 13 districts

${ }^{1}$ Institute for Health Policy, Colombo, Sri Lanka, ${ }^{2}$ UNICEF, Colombo, Sri Lanka and ${ }^{3}$ Medical Research Institute, Colombo, Sri Lanka.

Correspondence: RPRE, e-mail: <raviofficelk@gmail.com>. Received 18 June and revised version accepted 11 October 2012. Competing interests: Views expressed by authors in this article are not necessarily those of UNICEF. 